\title{
Mathematical modelling of bone remodelling cycles including the NFкB signalling pathway
}

Bing Ji, Yao Zhang, Changqing Zhen, Michael J Fagan, Qing Yang

Bing Ji, School of Control Science and Engineering, Shandong University, Jinan, 250061, P.R.China

Email: b.ji@sdu.edu.cn

Yao Zhang, School of Control Science and Engineering, Shandong University, Jinan, 250061, P.R.China

Email: yyao1228@163.com

Changqing Zhen, Shandong Provincial Hospital Affiliated to Shandong University, Jinan 250021, P.R. China

Email:zcq1521@163.com

Michael J Fagan, School of Engineering, University of Hull, Hull, HU6 7RX, UK

Email:m.j.fagan@hull.ac.uk

Qing Yang, Shandong Provincial Hospital Affiliated to Shandong University, Jinan, 250021, P.R. China

Email: qyangsdu@hotmail.com

\section{Corresponding author:}

Dr Qing Yang

Shandong Provincial Hospital Affiliated to Shandong University

Jinan, 250021, P.R. China

Tel: $\quad 008653188396813$

Fax: 008653188396813

Email: qyangsdu@hotmail.com 


\begin{abstract}
RANKL can promote the differentiation of osteoclast precursors into mature osteoclasts by binding to RANK expressed on the surfaces of osteoclast progenitor cells during bone remodelling. The NF- $\mathrm{B}$ signalling pathway is downstream of RANKL and transmits the RANKL signal to nuclear promoter-bound protein complexes from cell surface receptors, which then regulates target gene expression to facilitate osteoclastogenesis. However, this important role of the NF- $\kappa$ B signalling pathway is usually ignored in published mathematical models of bone remodelling. This paper describes the construction of a mathematical model of bone remodelling in a normal bone microenvironment with inclusion of the NF- $\mathrm{BB}$ signalling pathway. The model consisted of a set of ordinary differential equations and reconstructed variations in the bone cells, resultant bone volume, and biochemical factors involved in the NF-kB signalling pathway over time. The model was used to investigate how the NF-kB pathway is activated in osteoclast precursors to promote osteoclastogenesis during bone remodelling. Model simulations agreed well with published experimental data. It is hoped that this model can improve our understanding of bone remodelling. It has the obvious potential to examine the influence of NF- $\mathrm{kB}$ dysregulation on bone remodelling, and even propose potential therapeutic strategies to combat related bone diseases in future research.
\end{abstract}

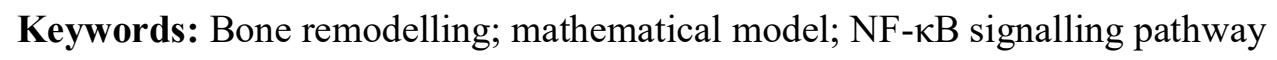




\section{INTRODUCTION}

Bone is a special tissue that experiences continuous repair, renewal, and adaptation throughout its lifetime via bone remodelling processes [1]. Studies have revealed that the RANK-RANKL-OPG pathway is an essential regulator during bone remodelling

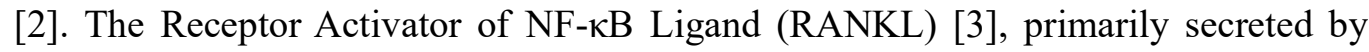
immature osteoblasts, can bind to the Receptor Activator of NF-kB (RANK) expressed on the surfaces of osteoclast progenitors, thereby the promoting differentiation of osteoclast precursors into mature osteoclasts. On the other hand, RANKL-regulated osteoclastogenesis can be inhibited by osteoprotegerin (OPG), which is secreted primarily by active osteoblasts and serves as a soluble decoy receptor for RANKL [4].

Nuclear factor-kappa B (NF- $\mathrm{B})$ refers to a transcription factor family containing

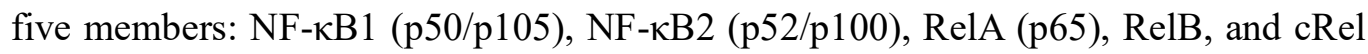

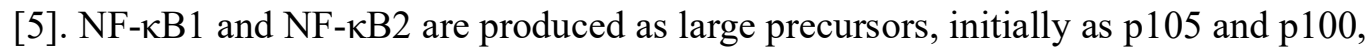
which then form mature subunits, p50 and p52, respectively [6]. Because p50 and p52 both lack a C-terminal transcription activation domain required for DNA binding, they dimerize RelA, RelB, and cRel to form heteromeric complexes. NF- $\mathrm{BB}$ is present in almost all cell types and plays an essential role in a number of physiological processes, including cytokine inflammation, immune response, cell proliferation, and survival [7]. $\mathrm{NF}-\kappa \mathrm{B}$ is tightly regulated and can be activated through two distinct signalling pathways: the canonical and non-canonical pathways. The canonical pathway, mediated by RelA/p50 heterodimers, is activated early in response to cytokines such as RANKL and TNF, and its activation is transient $[8,9]$. By contrast, the non-canonical pathway, related to the differentiation of p100 into p52, activates several hours later and lasts for

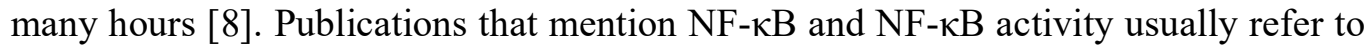




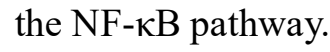

After the first discovery of NF-kB's role in bone cells in the mid-1990s, the following series of studies revealed that NF- $\mathrm{KB}$ serves as a downstream signalling pathway of RANKL [9-15] and is required for the formation of mature osteoclasts from their precursors rather than differentiation of myeloid cells into osteoclast precursors. After stimulation by RANKL, the canonical pathway is activated rapidly in osteoclast precursors [16] to promote the production of transcription factors necessary for osteoclastogenesis [17]. On the other hand, the non-canonical pathway is not needed for basal osteoclast formation [18] but is involved in enhancing osteoclastogenesis, for example, caused by metastatic cancer in bone and in inflammatory arthritis [9].

Mathematical models have been utilized by a number of researchers to improve our understanding of complicated biological processes, including bone remodelling, based on fragmented experimental data [4, 19-28]. These studies have indeed obtained many useful findings and demonstrated that mathematical modelling is an effective way to investigate complicated biological processes. However, NF- $\kappa \mathrm{B}$, which plays a very important role in osteoclastogenesis in the downstream signalling of RANKL, has thus far not been considered in these models of bone remodelling [4, 19-25]. In this context, this paper describes the construction of a mathematical model of bone remodelling by including the NF- $\mathrm{BB}$ pathway mechanism and its function in bone remodelling. The model can not only simulate the coupling between osteoclastic and osteoblastic lineages, but also can investigate how the NF- $\mathrm{kB}$ pathway is activated in osteoclast precursors and then regulates osteoclastogenesis after activation by RANKL. The model can potentially be used to examine the influence of NF-kB dysregulation on bone remodelling. It may even suggest potential therapeutic strategies for mitigating bone diseases in future research. 


\section{MODEL DEVELOPMENT}

\subsection{BASIC STRUCTURE OF THE MODEL}

A schematic diagram of the proposed model is shown in Figure 1, demonstrating how bone cells in the bone microenvironment cooperate during bone remodelling. The role of the NF- $\kappa \mathrm{B}$ signalling pathway is included in the model. The canonical NF- $\kappa \mathrm{B}$ pathway is activated in osteoclast precursors $\left(\mathrm{OC}_{\mathrm{p}}\right)$ by RANKL-RANK binding and then regulates osteoclastogenesis during bone remodelling, whereas the non-canonical pathway does not participate in basal osteoclast formation [18]. Thus, only the canonical pathway was considered in our model. For this reason, the NF- $\kappa$ B signalling pathway and NF- $\mathrm{kB}$ mentioned later in this paper refer only to the canonical pathway and the RelA/p50 heterodimer, respectively.

Figure 1 consists of two parts: part A describes the coupling mechanism between the osteoblastic and osteoclastic lineages during bone remodelling cycles, and part B presents how the RANKL signal is transmitted to the osteoclast precursors to promote osteoclastogenesis through the NF- $\mathrm{KB}$ signalling pathway. Osteoclastic and osteoblastic lineages contain several intermediate stages; however, our model only considers the important stages described in the model of Pivonka et al. [4]. To be specific, these are: uncommitted progenitors $\left(\mathrm{OB}_{\mathrm{u}}\right)$, osteoblast precursors $\left(\mathrm{OB}_{\mathrm{p}}\right)$, active osteoblasts $\left(\mathrm{OB}_{\mathrm{a}}\right)$, and apoptotic osteoblasts $\left(\mathrm{OB}_{\mathrm{ap}}\right)$ for the osteoblastic lineage; and osteoclast precursors $\left(\mathrm{OC}_{\mathrm{p}}\right)$, active osteoclasts $\left(\mathrm{OC}_{\mathrm{a}}\right)$, and apoptotic osteoclasts $\left(\mathrm{OC}_{\mathrm{ap}}\right)$ for the osteoclastic lineage. The interaction between osteoblastic and osteoclastic lineages was discussed in previous work $[4,23]$ and will not be elaborated here. This paper focuses on a discussion of how RANKL affects osteoclastogenesis through the NF- $\mathrm{BB}$ signalling pathway in $\mathrm{OC}_{\mathrm{p}}$ during bone remodelling. 
Part B presents the underlying mechanism by which the NF- $\kappa \mathrm{B}$ signalling pathway is activated in $\mathrm{OC}_{\mathrm{p}}$ by RANKL, and then regulates osteoclastogenesis. In resting or unstimulated cells, NF- $\mathrm{kB}$ heterodimers are inactivated and kept in the cytoplasm by

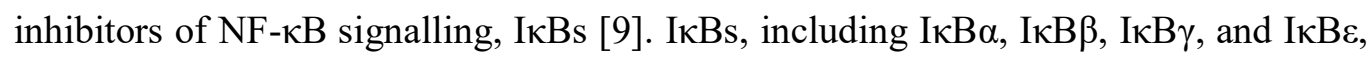
can bind to NF- $\kappa \mathrm{B}$ heterodimers and disturb their nuclear localization signals [8]. In

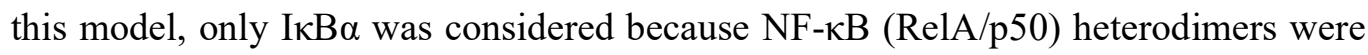
held primarily by $\mathrm{I} \kappa \mathrm{B} \alpha$. The NF- $\kappa \mathrm{B}$ signalling pathway is activated by the cytoplasmic $\mathrm{I} \kappa \mathrm{B} \alpha$ kinase (IKK), a trimeric complex consisting of $\operatorname{IKK} \alpha, \operatorname{IKK} \beta$, and $\operatorname{IKK} \gamma[10]$. In resting or un-stimulated $\mathrm{OC}_{\mathrm{p}}$ cells, IKK is neutral (denoted by $\mathrm{IKK}_{\mathrm{n}}$ ). Upon stimulation of RANKL, IKK is activated (denoted by $\mathrm{IKK}_{\mathrm{a}}$ ) and begins to phosphorylate $\mathrm{I} \kappa \mathrm{B} \alpha$, further leading to its polyubiquitination and degradation. This degradation releases NF$\kappa \mathrm{B}$ heterodimers. The free NF- $\kappa \mathrm{B}$ heterodimers then enter the nucleus from the cytoplasm and up-regulate transcription of c-Fos, NFATc1, and another two transcription factors required for osteoclastic precursor differentiation, as well as I $\mathrm{B} \alpha \alpha$ and A20, two inhibitors of the NF- $\mathrm{B}$ signalling pathway [29]. These inhibitors can then limit subsequent NF- $\kappa \mathrm{B}$ translocation and trigger a negative feedback loop. To be specific, the newly synthesized $I \kappa B \alpha$ enters the nucleus, renders the NF- $\kappa B$ heterodimers inactive, and returns them to the cytoplasm, whereas newly expressed A20 promotes the transformation of active IKK to into its inactive form (denoted by $\mathrm{IKK}_{\mathrm{i}}$ ), in which it is unable to phosphorylate $\mathrm{I} \kappa \mathrm{B} \alpha[30]$.

\subsection{MODEL EQUATIONS}

The model utilized nineteen ordinary differential equations (ODEs) to simulate the interaction between the osteoclastic and osteoblastic lineages, including the role of the NF- $\kappa$ B signalling pathway, as shown in Figure 1. The first four ODEs (Eqs. (1) - (4)) 
describe variations in the bone cells and bone volume over time, whereas the remaining fifteen ODEs (Eqs. (A1) - (A15)) represent the temporal variations of the biochemical factors involved in the NF-kB pathway. Following a series of models $[4,22,23,31]$ developed earlier for mimicking bone remodelling cycles, Eqs. (1) - (4), were constructed as follows:

$$
\begin{aligned}
& \frac{d}{d t} O B_{p}=D_{O B_{u}} \cdot \pi_{a c t, O B_{u}}^{T G F \beta} \cdot O B_{u}-D_{O B_{p}} \cdot \pi_{r e p, O B_{p}}^{T G F \beta} \cdot O B_{p} \\
& \frac{d}{d t} O B_{a}=D_{O B_{p}} \cdot \pi_{r e p, O B_{p}}^{T G F \beta} \cdot O B_{p}-A_{O B_{a}} \cdot O B_{a} \\
& \frac{d}{d t} O C_{a}=D_{O C_{p}} \cdot \pi_{a c t, O C_{p}}^{T F s} \cdot O C_{p}-\pi_{a c t, O C_{a}}^{T G F \beta} \cdot A_{O C_{a}} \cdot O C_{a} \\
& \frac{d}{d t} B V=-K_{r e s} \cdot O C_{a}+K_{\text {form }} \cdot O B_{a}
\end{aligned}
$$

where: $O B_{p}, O B_{a}, O C_{a}$, and $B V$ are four state variables, and $\frac{d O B_{p}}{d t}$ represents the temporal variations in $O B_{p}$, for example. The definition of variables and parameters used in Eqs. (1) - (4) are listed in Table 1 and Table 2. The model utilizes 'Hill functions' to simulate the functions of the ligand and receptor binding. 'Hill functions' are denoted by $\pi$ functions in the forms of $\pi_{a c t}$ and $\pi_{r e p}$, which represent the stimulating and inhibiting functions of the ligand-receptor binding, respectively. The definitions of 'Hill functions' used in the model are all described in detail in the Appendix A. Following the model of Pivonka et al. [4], $\pi_{a c t, O B_{u}}^{T G F \beta}$ and $\pi_{a c t, O C_{a}}^{T G F \beta}$ represent TGF- $\beta$ stimulating $O B_{u}$ differentiated into $O B_{p}$ and promoting the apoptosis of $O C_{a}$ respectively. $\pi_{r e p, O B_{p}}^{T G F \beta}$ describes that TGF- $\beta$ suppresses the differentiation of $O B_{p}$ into $O B_{a}$. TGF$\beta$ represents the concentration of TGF- $\beta$. The definitions of the TGF- $\beta$ concentration and $\pi$ functions are listed in Tables A1 and A2 of the Appendix A, respectively.

As discussed above, NF- $\mathrm{BB}$ plays a pivotal role in osteoclastogenesis; however, it has been ignored in prior models $[4,22,23,31]$. The distinct feature of our model is the 
introduction of a new $\pi$ function, denoted by $\pi_{a c t, O C_{p}}^{T F s}$, which represents the stimulation of $O C_{p}$ differentiation into $O C_{a}$ by NF- $\mathrm{BB}$-regulated transcription factors, including c-Fos, NFATc1, and other factors. The definition of $\pi_{a c t, O C_{p}}^{T F s}$ is as follows:

$$
\pi_{a c t, O C_{p}}^{T F s}=\frac{T F s}{T F s+K_{D, T F s, a c t}}
$$

where represents the concentration of NF- $\mathrm{KB}$-regulated transcription factors and $K_{D, T F s, a c t}$ represents the activation coefficient related to binding on $O C_{p}$. The calculation of the concentration requires mathematical modelling of the NF- $\mathrm{BB}$ signalling pathway. Here, a mathematical model developed by Lipniacki et al. [29] was extended to mimic the NF- $\mathrm{kB}$ signalling pathway as depicted in Figure 1. The extended model consists of fifteen ODEs, including Eqs. (A1) - (A15) in the Appendix A, and describes the temporal variations in the biochemical factors involved in the NF- $\kappa \mathrm{B}$ signalling pathway. For example, $\frac{d}{d t} K K \quad$ ( ) indicates the variations in $K K$ over time.

This extended model includes two important additional features: firstly, the effect of RANKL is included in Eqs. (A1) - (A3) to replace the effect of TNF, because NF$\kappa \mathrm{B}$ signalling is activated rapidly in osteoclast precursors in response to RANKL [16]. Secondly, the model of Lipniacki et al. [29] only considered the presence or absence of TNF (represented by ' 1 ' or ' 0 ' respectively), but ignored the effects of its concentration. By contrast, our model considered the effects of the RANKL concentration, with $f 1$ and $f_{2}$ in Eqs. (A1) - (A3) representing the role of RANKL in IKKn transformed into IKKa and IKKa transformed into IKKi, respectively. The definitions of $f$ 1 and $f 2$ are:

$$
{ }_{f 1}={ }_{R} * \pi_{a c t, I K K_{n}}^{R A N K L}
$$




$$
\begin{aligned}
f 2 & ={ }^{*} \pi_{\text {act,IKKa }}^{\text {RANKL }} \\
\pi_{a c t, I K K_{n}}^{\text {RANKL }} & =\frac{R A N K L}{A K+K_{D}, \text { RANKL,act }} \\
\pi_{\text {act }, I K K_{a}}^{\text {RANKL }} & =\frac{R A N K L}{A K+K_{D I 2, R A N K L, a c t}}
\end{aligned}
$$

$\pi_{a c t, I K K_{n}}^{R A N K L}$ represents RANKL promoting IKKn transformed into IKKa, while $\pi_{a c t, I K K_{n}}^{R A N K L}$ denotes RANKL inducing IKKa transformed into IKKi through A20. The value of ${ }_{R}$ is 0 or 1 , indicating the absence or presence of RANKL, respectively. RANKL represents the concentration of RANKL, the definition of which is included in Table A1 of the Appendix A.

Thus, a new $\pi$ function $\pi_{a c t, O C_{p}}^{T F s}$, together with fifteen ODEs, are introduced into the model of bone remodelling to simulate the underlying mechanism in which the RANKL signal is transmitted and then affects osteoclastogenesis through the NF- $\mathrm{BB}$ signalling pathway.

\section{RESULTS}

The definitions and values of all parameters in the model equations are all described in detail in Table 2 and Table 3. Following the work of [25], a genetic algorithm (GA) was used to predict values of the model parameters lacking experimental data or without biological meaning based on the other related estimated or known parameter values. Different combinations of these unknown model parameters corresponded to various model outputs. GAs are an effective approach to search for parameter values in parameter space corresponding to preferred model outputs [25]. In this work, model outputs refer to the concentrations of bone cells in the steady state under the normal bone microenvironment. Preferred values are listed in Table 4 in reference to the publish data (the detailed information of GA is described in detail in the Appendix A). The GA 
was carried out using the genetic algorithm solver, and the model equations were solved using the ode23 solver in the Matlab software package (R2015b, Mathworks, Natick, USA).

Figure 2A shows the temporal variations of RANKL during bone remodelling, while Figures $2 \mathrm{~B}-2 \mathrm{H}$ and Figure 3 demonstrate the variations in concentrations of the fifteen biochemical factors involved in the NF- $\mathrm{kB}$ signalling pathway over time, after activation by RANKL. Figures 4-8 reveal how the variations of RANKL by injection (10 or $20 \mathrm{pM} /$ day) or inhibition (by $5 \%$ or $10 \%$ ) influenced free nuclear NF-kB, , bone cells, the $\mathrm{OBa}$ OCa ratio, and bone volume, respectively. It is known that the OBa:OCa ratio has an important influence on the bone volume during bone remodelling. Figures 7 and 8 illustrate how that ratio and bone volume vary due to RANKL changes, respectively.

\section{DISCUSSION}

The model was constructed to analyze bone remodelling cycles by including the role of the NF- $\mathrm{KB}$ signalling pathway. It can not only reconstruct the variations in the bone cell concentrations, resultant bone volume and the biochemical factors involved in the NF$\kappa \mathrm{B}$ signalling pathway in the bone microenvironment over time, but also investigate how variations in the RANKL concentration affected bone cells and the resultant bone volume through the NF- $\mathrm{B}$ signalling pathway. Experimental observations demonstrated that the concentrations of bone cells and bone volume remained in a dynamic steady state under normal conditions [22, 32]. This steady state can be disturbed in bone-related diseases, such as metastatic bone disease. Simulation results based on the model presented in this paper indicated that concentrations of $\mathrm{OB}_{\mathrm{p}}, \mathrm{OB}_{\mathrm{a}}$, and $\mathrm{OC}_{\mathrm{a}}$ and bone volume all remained constant over time. These results agreed well 
with the experimental observations.

The binding of RANKL to RANK expressed on $\mathrm{OC}_{\mathrm{p}}$ stimulates the NF- $\mathrm{kB}$ signalling pathway in $\mathrm{OC}_{\mathrm{p}}$, which then promotes the differentiation of $\mathrm{OC}_{\mathrm{p}}$ into $\mathrm{OC}_{\mathrm{a}}$. The temporal variations in the biochemical factors involved in the NF- $\mathrm{KB}$ signalling pathway, as illustrated in Figures $2 \mathrm{~B}-2 \mathrm{H}$ and Figure 3, agreed well with the work of Lipniacki et al. [29]. Figures $4-8$ help to explain the underlying mechanism in which how RANKL regulates osteoclastogenesis through the NF- $\mathrm{BB}$ signalling pathway and further influences osteoblast concentrations and the resultant bone volume during bone remodelling. As shown in Figure 4, the rising level of RANKL causes an initial rapid increase in the concentration of free nuclear NF- $\mathrm{BB}$ until it reaches a new stable state higher than its initial value. This simulation result was confirmed by experimental observations that the canonical NF- $\kappa \mathrm{B}$ pathway is activated rapidly in $\mathrm{OC}_{\mathrm{p}}$ in response to RANKL, causing a quick and transient increase in NF- $\mathrm{KB}$ expression levels $[9,33]$.

On the other hand, the inhibition of RANKL results in a rapid drop in the free nuclear NF- $\mathrm{KB}$ concentration, which then remains at a lower concentration. The increase or decrease in the free NF- $\mathrm{BB}$ in the nucleus thereafter promotes or inhibits transcription of required for osteoclastic precursor differentiation, as shown in Figure 5, which again agrees with the experimental data of Takayanagi et al. [34]. The changes in the concentrations directly trigger variations of osteoblastic cells as well as indirectly affecting osteoclastic cells, because the osteoblastic and osteoclastic lineages are tightly coupled [17]. These fluctuations in the bone cells are illustrated in Figure 6, confirming that increasing levels of RANKL lead to a rise in $\mathrm{OB}_{\mathrm{p}}$ and $\mathrm{OC}_{\mathrm{a}}$, followed by a less pronounced increase in $\mathrm{OB}_{\mathrm{a}}$. On the other hand, the drop in RANKL levels produces the opposite effects in the osteoblastic and osteoclastic cells. Figure 6 also suggests that a given change in RANKL can produce different degrees of variations 
in the different bone cell types.

As shown in Figure 7, the OBa:OCa ratio undergoes an initial decrease (or increase) and then returns to a stable level that is lower (or higher) than its initial value in response to the injection ( 10 or $20 \mathrm{pM} /$ day) or inhibition (by $5 \%$ or $10 \%$ ) of RANKL, respectively. These changes lead to a corresponding gradual decrease (or increase) in bone volume (shown in Figure 8). These simulation results agreed with experimental observations $[35,36]$. The simulation results shown in Figures $4-8$ also suggested that the effect of the injection or inhibition of RANKL on free nuclear NF- $\mathrm{BB}, \quad$, cell concentrations, bone volume and the OBa:OCa ratio is positively linked to the injection or inhibition rate (e.g., a $20 \mathrm{pM} /$ day RANKL injection rate leads to greater variations in the cell concentrations, bone volume, and $\mathrm{OBa}: \mathrm{OCa}$ ratio than a $10 \mathrm{pM} /$ day injection rate). In addition, the simulation results also showed that NF- $\mathrm{kB}, \quad$, cell concentrations, and the OBa:OCa ratio, but not the bone volume, all achieved a new state of equilibrium that was higher or lower than their initial levels after a rapid and transient increase or decrease due to the injection or inhibition of RANKL, respectively.

\section{CONCLUSION}

Bone remodelling is a very important biological process, and its dysregulation is related to several bone diseases. Improving our understanding of bone remodelling and the complex cellular interactions involved would be helpful for the development of new strategies for combating bone-related diseases. Mathematical modelling, supported with partial experimental findings, is an effective approach to analyze this type of multilayered biological system, and several mathematical models of bone remodelling have been constructed. To our knowledge, however, mathematical models published to date have failed to consider the role of the NF-kB signalling pathway in bone remodelling. Here, a mathematical model was developed to reconstruct the bone remodelling process 
under normal conditions by including the effects of the NF- $\mathrm{BB}$ signalling pathway.

In addition to predicting bone cell concentrations and the bone volume, the model also reconstructed the temporal behaviors of the biochemical factors involved in the $\mathrm{NF}-\kappa \mathrm{B}$ signalling pathway during bone remodelling. The simulation results agreed well with the published experimental data. This model investigated the underlying mechanisms of the NF- $\kappa \mathrm{B}$ pathway effects in RANKL-regulated osteoclastogenesis by observing the influence of the variations of RANKL concentration on the bone cells and the resultant bone volume through the NF- $\mathrm{kB}$ signalling pathway. This observation helps explain how the NF- $\mathrm{KB}$ signalling pathway is activated by RANKL in OCp and then transmits signals emanating from cell surface receptors to nuclear promoter-bound protein complexes, thereby further regulating target gene expression during bone remodelling cycles.

Abnormalities in NF-kB are found in several bone diseases, and it is hoped that this model can serve as a collaborative tool, in combination with experimental findings, to evaluate potential therapeutic interventions and even propose new therapeutic targets for bone-related diseases caused by the dysregulation of the NF- $\kappa \mathrm{B}$ pathway. For example, dehydroxymethylepoxyquinomicin (DHMEQ) was designed as an NF- $\mathrm{B}$ inhibitor [37] and has been shown to limit RANKL-induced osteoclast differentiation. Its mechanism was initially unknown, although biochemical analysis now indicates that the inhibition of NF- $\mathrm{KB}$ suppresses osteoclastogenesis by down-regulating NFATc1 [38]. However, according to our model simulations, we find that NF- $\kappa \mathrm{B}$, being downstream of RANKL, has a direct influence on RANKL-regulated osteoclastogenesis by regulating transcription factors, which explains why DHMEQ inhibits osteoclastogenesis so well. 


\section{DATA ACCESSIBILITY}

Matlab code is available at https://pan.baidu.com/s/1G56TW8SM6PMSxlETFI56RQ

\section{COMPETING INTERESTS}

We declare that we have no competing interests.

\section{ACKNOWLEDGEMENT}

This work was partly supported by National Natural Science Foundation of China through grants 61673246 and 81301294, and the key research and development program of Shandong Province through grant 2016GSF201168. 


\section{REFERENCES}

[1] Parfitt M A. Osteonal and hemi-osteonal remodeling: the spatial and temporal framework for signal traffic in adult human bone. Journal of Cellular Biochemistry 55, 273-286.(doi:10.1002/jcb.240550303)

[2] Boyle WJ, Simonet WS, Lacey DL. 2003 Osteoclast differentiation and activation. Nature 423, 337. (doi:10.1038/nature01658)

[3] Gittoes NJ, Franklyn JA. 1998 Hyperthyroidism. Current treatment guidelines. Drugs 55, 543-53.(doi: 10.2165/00003495-199855040-00005)

[4] Pivonka P, Zimak J, Smith D W, et al. 2008 Model structure and control of bone remodeling: A theoretical study. Bone 43, 249263.(doi:10.1016/j.bone.2008.03.025)

[5] Beauparlant P. 1996 Control of Gene Expression and Cell Growth by the NFkBIkB Family of Transcription Regulators. McGill University Libraries.

[6] Karin M, Greten F R. 2005 NF-kappa B: linking inflammation and immunity to cancer development and progression. Nature Reviews Immunology 5, 749759.(doi: 10.1038/nri1703)

[7] Vallabhapurapu S, Karin M. 2009 Regulation and function of NF- $\kappa B$ transcription factors in the immune system. Annual review of immunology 27, 693-733.(doi: 10.1146/annurev.immunol.021908.132641)

[8] Boyce BF, Xing L. 2007 Biology of RANK, RANKL, and osteoprotegerin. Arthritis Research \& Therapy 9, S1-S1.(doi: 10.1186/ar2165)

[9] Boyce BF, Xiu Y, Li J, Xing L, Yao Z. 2015 NF-kB-mediated regulation of osteoclastogenesis. Endocrinology and metabolism 30, 35-44.(doi: 10.3803/EnM.2015.30.1.35)

[10] Beg A A, Sha W C, Bronson R T, Ghosh S, Baltimore D. 1995 Embryonic lethality and liver degeneration in mice lacking the RelA component of NFkappa B. Nature 376, 167-170.

[11] Franzoso G, Carlson L, Xing L, Poljak L, Shores EW, Brown KD, et al. 1997

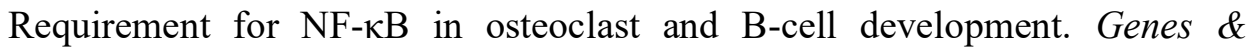
development 11, 3482-3496.(doi: 10.1101/gad.11.24.3482)

[12] Lacey D L, Timms E, Tan H L, Kelley J M, Dunstan R C, Burgess T, et al. 1998 Osteoprotegerin Ligand Is a Cytokine that Regulates Osteoclast Differentiation and Activation. Cell 93, 165-76.(doi: 10.1016/S0092-8674(00)81569-X)

[13] Yasuda H, Shima N, Nakagawa N, Yamaguchi K, Kinosaki M, Mochizuki S, et al. 1998 Osteoclast differentiation factor is a ligand for osteoprotegerin/osteoclastogenesis-inhibitory factor and is identical to TRANCE/RANKL. Proceedings of the National Academy of Sciences of the United States of America 95, 3597-3602.(doi: 10.2307/44528)

[14] Li J, Sarosi I, Yan X Q, Morony S, Capparelli C, Tan L H, et al. 2000 RANK is the intrinsic hematopoietic cell surface receptor that controls osteoclastogenesis and regulation of bone mass and calcium metabolism. Proc Natl Acad Sci U S A 97, 1566-1571.(doi: 10.1073/pnas.97.4.1566) 
[15] Lianping X, Bushnell T P, Louise C, Zhenxing T, Mehrdad T, Ulrich S, et al. 2010 NF-kappaB p50 and p52 expression is not required for RANK-expressing osteoclast progenitor formation but is essential for RANK- and cytokinemediated osteoclastogenesis. Journal of Bone \& Mineral Research 17, 12001210.(doi: 10.1359/jbmr.2002.17.7.1200)

[16] Otero J E, Dai S, Alhawagri Muhammad A, et al. 2010 IKKbeta activation is sufficient for RANK-independent osteoclast differentiation and osteolysis. Journal of Bone and Mineral Research 25, 1282-1294.(doi: 10.1002/jbmr.4)

[17] Palombella V J, Rando O J, Goldberg A L, Maniatis T. 1994 The ubiquitinproteasome pathway is required for processing the NF-kappa B1 precursor protein and the activation of NF-kappa B. Cell 78, 773-785.(doi: 10.1016/S0092-8674(94)90482-0)

[18] Jimi E, Aoki H K, D'Acquisto F, May J M, Nakamura I, Sudo T, et al. 2004 Selective inhibition of NF-kappa B blocks osteoclastogenesis and prevents inflammatory bone destruction in vivo. Nature Medicine 10, 617-624.(doi: 10.1586/14787210.5.1.77)

[19] Kroll M H. 2000 Parathyroid Hormone Temporal Effects on Bone Formation and Resorption. Bulletin of Mathematical Biology 62, 163-188.(doi: 10.1006/bulm.1999.0146)

[20] Komarova S, Smith R J, Dixon S J, Sims S M, Wahl L M. 2003 Mathematical model predicts a critical role for osteoclast autocrine regulation in the control of bone remodeling. Bone 33, 206-215.(doi: 10.1016/S8756-3282(03)00157-1)

[21] Rattanakul C, Lenbury Y, Krishnamara N, Wollkind D J. 2003 Modeling of bone formation and resorption mediated by parathyroid hormone: response to estrogen/PTH therapy. Biosystems 70, 55-72.(doi: 10.1016/s03032647(03)00040-6)

[22] Vincent L, Tobin F L, Greller L D, Cho C R, Suva L J. 2004 Modeling the interactions between osteoblast and osteoclast activities in bone remodeling. Journal of Theoretical Biology 229, 293-309.(doi: 10.1016/j.jtbi.2004.03.023)

[23] Pivonka P, Zimak J, Smith D W, Gardiner B S, Dunstan R C, Sims A N, et al. 2010 Theoretical investigation of the role of the RANK-RANKL-OPG system in bone remodeling. Journal of Theoretical Biology, 262, 306-316.(doi: 10.1016/j.jtbi.2009.09.021)

[24] Ryser M D, Komarova S V, Nigam N. 2010 THE CELLULAR DYNAMICS OF BONE REMODELING: A MATHEMATICAL MODEL. Siam Journal on Applied Mathematics 70, 1899-1921.(doi: 10.1137/090746094)

[25] Ji B. 2012 A novel mathematical model of bone remodelling cycles for trabecular bone at the cellular level. Biomechanics \& Modeling in Mechanobiology 11, 973-982.(doi: 10.1007/s10237-011-0366-3)

[26] Cook L M, Araujo A, Pow-Sang JM, et al. 2016Predictive computational modeling to define effective treatment strategies for bone metastatic prostate cancer. Scientific Reports 6. (doi:10.1038/srep29384) 
[27] Baiotto S, Labat B, Vico L, et al. 2008 Bone remodeling regulation under unloading conditions: Numerical investigations. Computers in Biology and Medicine 39. 46-52. (doi:10.1016/j.compbiomed.2008.10.008)

[28] Buenzli P R, Pivonka P, Gardiner B S et al. 2012 Modelling the anabolic response of bone using a cell population model. Journal of Theoretical Biology 307, 42-52. (doi:10.1016/j.jtbi.2012.04.019)

[29] Tomasz L, Pawel P, Brasier A R, Bruce L, Marek K. 2004 Mathematical model of NF-kappaB regulatory module. Journal of Theoretical Biology 228, 195215.(doi:10.1016/j.jtbi.2004.01.001)

[30] Basak S, Behar M, Hoffmann A. 2012 Lessons from mathematically modeling the NF- $\mathrm{B}$ pathway. Immunological Reviews 246, 221-238.(doi: 10.1111/j.1600-065x.2011.01092.x)

[31] Ji B, Genever P G, Patton R J, Fagan M J. 2014 Mathematical modelling of the pathogenesis of multiple myeloma-induced bone disease. International journal for numerical methods in biomedical engineering 30, 1085-1102.(doi: 10.1002/cnm.2645)

[32] Zumsande M, Stiefs D, Siegmund S, Gross T. 2011 General analysis of mathematical models for bone remodeling. Bone 48, 910-917.(doi: 10.1016/j.bone.2010.12.010)

[33] Asagiri M, Sato K,Usami T, et al. 2005 Autoamplification of NFATc1 expression determines its essential role in bone homeostasis. Journal of Experimental Medicine 202, 1261-9.( doi:10.1084/jem.20051150)

[34] Takayanagi H, Kim S, Koga T, Nishina H, Isshiki M, Yoshida H, et al. 2002 Induction and Activation of the Transcription Factor NFATc1 (NFAT2) Integrate RANKL Signaling in Terminal Differentiation of Osteoclasts. Developmental Cell 3, 889-901.(doi: 10.1016/s1534-5807(02)00369-6)

[35] Filvaroff E, Derynck R. 1998 Bone remodelling: a signalling system for osteoclast regulation. Current Biology Cb 8, 679-82.(doi: 10.1016/s09609822(98)70434-8)

[36] Manolagas S C. 2000 Birth and death of bone cells: basic regulatory mechanisms and implications for the pathogenesis and treatment of osteoporosis. Endocrine reviews 21, 115-137.(doi: 10.1210/edrv.21.2.0395)

[37] Miyajima A, Kosaka T, Seta K, Asano T, Umezawa K, Hayakawa M. 2003 Novel Nuclear Factor $\kappa$ B Activation Inhibitor Prevents Inflammatory Injury in Unilateral Ureteral Obstruction. Journal of Urology 169, 1559-1563.(doi: 10.1097/01.ju.0000045686.21766.c1)

[38] Takatsuna H, Asagiri M, Kubota T, Oka K, Osada T, Sugiyama C, et al. 2005 Inhibition of RANKL-Induced Osteoclastogenesis by (-)-DHMEQ, a Novel NF- $\mathrm{kB}$ Inhibitor, Through Downregulation of NFATc1. Journal of Bone and Mineral Research 20, 653-662.(doi: 10.1359/JBMR.041213)

[39] Caplan A I. 2007 Adult mesenchymal stem cells for tissue engineering versus regenerative medicine. Journal of cellular physiology 213, 341-347.(doi: 10.1002/jcp.21200) 
[40] Silva A S , Gatenby R A. 2010 A theoretical quantitative model for evolution of cancer hemotherapy resistance. Biology direct 5, 25.(doi: 10.1186/1745-61505-25)

[41] Lerner U H. 2004 New molecules in the tumor necrosis factor ligand and receptor superfamilies with importance for physiological and pathological bone resorption. Critical Reviews in Oral Biology \& Medicine 15, 64-81.(doi: $10.1177 / 154411130401500202$ ) 
Table 1: Definitions of variables used in the model.

\begin{tabular}{|c|c|}
\hline Parameter & Description \\
\hline$O B_{u}$ & Uncommitted osteoblast progenitors \\
\hline$O B_{p}$ & Osteoblast precursors \\
\hline$O B_{a}$ & Active osteoblasts \\
\hline$O C_{p}$ & Osteoclast precursors \\
\hline$O C_{a}$ & Active osteoclasts \\
\hline$B V$ & The normalized bone volume \\
\hline$K K$ & Cytoplasmic concentration of neutral $K K$ kinase \\
\hline$K K$ & Cytoplasmic concentration of active $K K$ kinase \\
\hline$K K$ & Cytoplasmic concentration of inactive $K K$ kinase \\
\hline$B$ & Cytoplasmic concentration of \\
\hline$B_{n}$ & Nuclear concentration of \\
\hline$A 20$ & Cytoplasmic concentration of $A 20$ \\
\hline$A 20_{t}$ & $\begin{array}{l}\text { Concentration of } A 20 \text { mRNA transcript calculated per } \\
\text { cytoplasmic volume }\end{array}$ \\
\hline$B$ & Cytoplasmic concentration of $B$ \\
\hline$B \alpha_{n}$ & Nuclear concentration of $B$ \\
\hline$B \quad \alpha_{t}$ & $\begin{array}{l}\text { Concentration of } B \quad \text { mRNA transcript calculated per } \\
\text { cytoplasmic volume }\end{array}$ \\
\hline$K K \quad \mid B$ & Cytoplasmic concentration of complexes of $K K$ and $B$ \\
\hline \begin{tabular}{l|l}
$B$ & $B$
\end{tabular} & Cytoplasmic concentration of complexes of $B$ and $B$ \\
\hline$B \alpha_{n} \mid B_{n}$ & Nuclear concentration of complexes of $\quad B \quad$ and $B \alpha$ \\
\hline$K K \quad|B| B$ & $\begin{array}{l}\text { Cytoplasmic concentration of complexes of } K K, B \text { and } \\
\quad B\end{array}$ \\
\hline & Concentration of NF- $\mathrm{KB}$ regulated transcription factors \\
\hline
\end{tabular}


Table 2: Definitions of model parameters used in the model.

\begin{tabular}{|c|c|c|c|}
\hline Parameter & Description & Parameter & Description \\
\hline$D_{O B_{u}}$ & $\begin{array}{l}\text { Differentiation rate of osteoblast } \\
\text { progenitors }\end{array}$ & $\alpha$ & $\begin{array}{l}\text { TGF- } \beta \text { content stored in } \\
\text { bone matrix }\end{array}$ \\
\hline$D_{O B_{p}}$ & $\begin{array}{l}\text { Differentiation rate of osteoblast } \\
\text { precursors }\end{array}$ & $\widetilde{D}_{T G F \beta}$ & Rate of degradation of \\
\hline$A_{O B_{a}}$ & $\begin{array}{l}\text { Rate of elimination of active } \\
\text { osteoblasts }\end{array}$ & PTH & $\begin{array}{l}\text { Rate of synthesis of } \\
\text { systemic PTH }\end{array}$ \\
\hline$D_{O C_{p}}$ & $\begin{array}{l}\text { Differentiation rate of osteoclast } \\
\text { precursors }\end{array}$ & $\widetilde{D}_{P T H}$ & $\begin{array}{l}\text { Rate of degradation of } \\
\text { PTH }\end{array}$ \\
\hline$A_{O C_{a}}$ & $\begin{array}{l}\text { Rate of elimination of active } \\
\text { osteoclasts }\end{array}$ & $O P G$ & $\begin{array}{l}\text { Minimum rate of } \\
\text { production of OPG per } \\
\text { active osteoblast }\end{array}$ \\
\hline$K_{D 1, T G F \beta}$ & $\begin{array}{l}\text { Activation coefficient related to } \\
\text { growth factors binding on } O B_{u}\end{array}$ & $\widetilde{D}_{O P G}$ & $\begin{array}{l}\text { Rate of degradation of } \\
\text { OPG }\end{array}$ \\
\hline$K_{D 2, T G F \beta}$ & $\begin{array}{l}\text { Repression coefficient related to } \\
\text { growth factors binding on } O B_{p}\end{array}$ & $O \quad \max$ & $\begin{array}{l}\text { Maximum possible OPG } \\
\text { concentration }\end{array}$ \\
\hline$K_{D 3, T G F \beta}$ & $\begin{array}{l}\text { Activation coefficient related to } \\
\text { growth factors binding on } O C_{a}\end{array}$ & $R A N K L$ & $\begin{array}{l}\text { Production rate of RANKL } \\
\text { per cell }\end{array}$ \\
\hline$K_{D 1, P T H}$ & $\begin{array}{l}\text { Activation coefficient for } \\
\text { RANKL production related to } \\
\text { PTH binding }\end{array}$ & $\widetilde{D}_{R A N K L}$ & $\begin{array}{l}\text { Rate of degradation of } \\
\text { RANKL }\end{array}$ \\
\hline$K_{D 2, P T H}$ & $\begin{array}{l}\text { Repression coefficient for OPG } \\
\text { production related to PTH } \\
\text { binding }\end{array}$ & $R A N K L$ & $\begin{array}{l}\text { Maximum number of } \\
\text { RANKL on the surface of } \\
\text { each osteoblastic precursor }\end{array}$ \\
\hline
\end{tabular}


Table 2(cont): Definitions of model parameters used in the model.

\begin{tabular}{|l|l|c|l|}
\hline$K_{D, R A N K L}$ & $\begin{array}{l}\text { Activation coefficient related to } \\
\text { RANKL binding to RANK }\end{array}$ & $K_{A, R A N K}$ & $\begin{array}{l}\text { Association rate constant } \\
\text { for RANKL binding to } \\
\text { RANK. }\end{array}$ \\
\hline$K_{D, T F s, a c t}$ & $\begin{array}{l}\text { Activation coefficient for } 0 C_{p} \\
\text { differentiation related to } \\
\text { binding }\end{array}$ & $K_{r e s}$ & $\begin{array}{l}\text { Relative rate of bone } \\
\text { resorption (normalized } \\
\text { with respect to normal } \\
\text { bone resorption) }\end{array}$ \\
\hline$K_{D I 1, T F s, a c t}$ & $\begin{array}{l}\text { Activation coefficient for } K K \\
\text { transformation related to } \\
\text { RANKL binding to RANK }\end{array}$ & $K_{f o r m}$ & $\begin{array}{l}\text { Relative rate of bone } \\
\text { formation (normalized } \\
\text { with respect to normal } \\
\text { bone resorption) }\end{array}$ \\
\hline$K_{D}, T F s$, act & $\begin{array}{l}\text { Activation coefficient for } K K \\
\text { transformation related to } \\
\text { RANKL binding to RANK }\end{array}$ & $K_{A, O P G}$ & $\begin{array}{l}\text { Association rate constant } \\
\text { for RANKL binding to } \\
\text { OPG }\end{array}$ \\
\hline
\end{tabular}


Table 3: Values of model parameters and sources.

\begin{tabular}{|c|c|c|c|}
\hline Parameter & Value & Parameter & Value \\
\hline$D_{O B_{u}}$ & $3.24 \mathrm{e}+2 /$ day(estimated $)$ & $\alpha$ & $1.00 \mathrm{pM} / \%[28]$ \\
\hline$D_{O B_{p}}$ & 3.67e-1/day(estimated) & $\widetilde{D}_{T G F \beta}$ & $2.00 \mathrm{e}+2 /$ day $[28]$ \\
\hline$A_{O B_{a}}$ & $3.00 \mathrm{e}-1 /$ day $[4,28]$ & PTH & $9.74 \mathrm{e}+2 \mathrm{pM} /$ day $[28]$ \\
\hline$D_{O C_{p}}$ & $1.73 \mathrm{e}-1 /$ day(estimated) & $\widetilde{D}_{P T H}$ & $3.84 \mathrm{e}+2 /$ day $[28]$ \\
\hline$A_{O C_{a}}$ & 1.20 /day [4] & $O P G$ & $5.02 \mathrm{e}+6 /$ day (estimated) \\
\hline$K_{D 1, T G F \beta}$ & $\begin{array}{l}4.825 \mathrm{e}-4 \mathrm{pM} \\
\text { (calculation by GA) }\end{array}$ & $\widetilde{D}_{O P G}$ & $4.16 /$ day [28] \\
\hline$K_{D 2, T G F \beta}$ & $2.19 \mathrm{e}-4 \mathrm{pM}[28]$ & $O \quad \max$ & $7.98 \mathrm{e}+2 \mathrm{pM}[28]$ \\
\hline$K_{D 3, T G F \beta}$ & $\begin{array}{l}\text { 9.33e-5 pM } \\
\text { (calculation by GA) }\end{array}$ & $R A N K L$ & $8.25 \mathrm{e}+5 /$ day (estimated) \\
\hline$K_{D 1, P T H}$ & $\begin{array}{l}2.09 \mathrm{e}+1 \mathrm{pM} \\
\text { (calculation by GA) }\end{array}$ & $\widetilde{D}_{R A N K L}$ & $4.16 /$ day [28] \\
\hline$K_{D 2, P T H}$ & $2.21 \mathrm{e}-1 \mathrm{pM}[4]$ & $R A N K L$ & $3.00 \mathrm{e}+6[28]$ \\
\hline$K_{D, R A N K L}$ & $4.12 \mathrm{e}+1 \mathrm{pM}$ (estimated) & $K_{A, R A N K}$ & $7.19 \mathrm{e}-2 / \mathrm{pM}[28]$ \\
\hline$K_{D, T F s, a c t}$ & $\begin{array}{l}6.5 \mathrm{e}-4 \mathrm{pM} \\
\text { (calculation by GA) }\end{array}$ & $K_{\text {res }}$ & $\begin{array}{l}1.92 \mathrm{e}+2 /(\mathrm{pM} * \text { day }) \\
\text { (calculation by GA) }\end{array}$ \\
\hline$K_{D I 1, T F s, a c t}$ & $\begin{array}{l}2.5 \mathrm{pM} \\
\text { (calculation by GA) }\end{array}$ & $K_{\text {form }}$ & $3.31 \mathrm{e}+1 /(\mathrm{pM} *$ day $)[28]$ \\
\hline$K_{D I 2, T F s, a c t}$ & $\begin{array}{l}2.5 \mathrm{pM} \\
\text { (calculation by GA) }\end{array}$ & $K_{A, O P G}$ & $5.68 \mathrm{e}-2 / \mathrm{pM}[28]$ \\
\hline
\end{tabular}

Note: $\mathrm{GA}=$ genetic algorithm 
Table 4: Values of cell concentrations.

\begin{tabular}{|c|c|c|}
\hline Variables & Values & Unit \\
\hline$O B_{u}$ & $3.27 \mathrm{e}-6[39]$ & $\mathrm{pM}$ \\
\hline$O B_{p}$ & $7.63 \mathrm{e}-4[40]$ & $\mathrm{pM}$ \\
\hline$O B_{a}$ & $6.33 \mathrm{e}-4[41]$ & $\mathrm{pM}$ \\
\hline$O C_{p}$ & $1.28 \mathrm{e}-3[1]$ & $\mathrm{pM}$ \\
\hline$O C_{a}$ & $1.04 \mathrm{e}-4[41]$ & $\mathrm{pM}$ \\
\hline
\end{tabular}




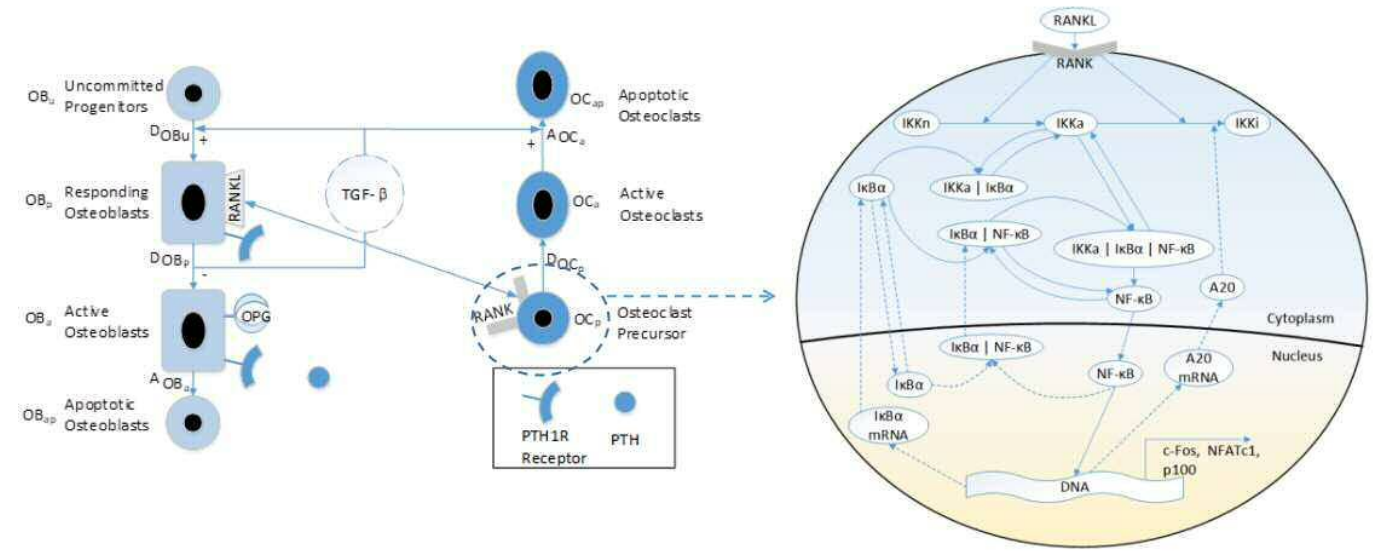

Figure 1: Interaction between osteoclastic and osteoblastic lineages including the canonical NF- $\mathrm{KB}$ signalling pathway during bone remodelling.
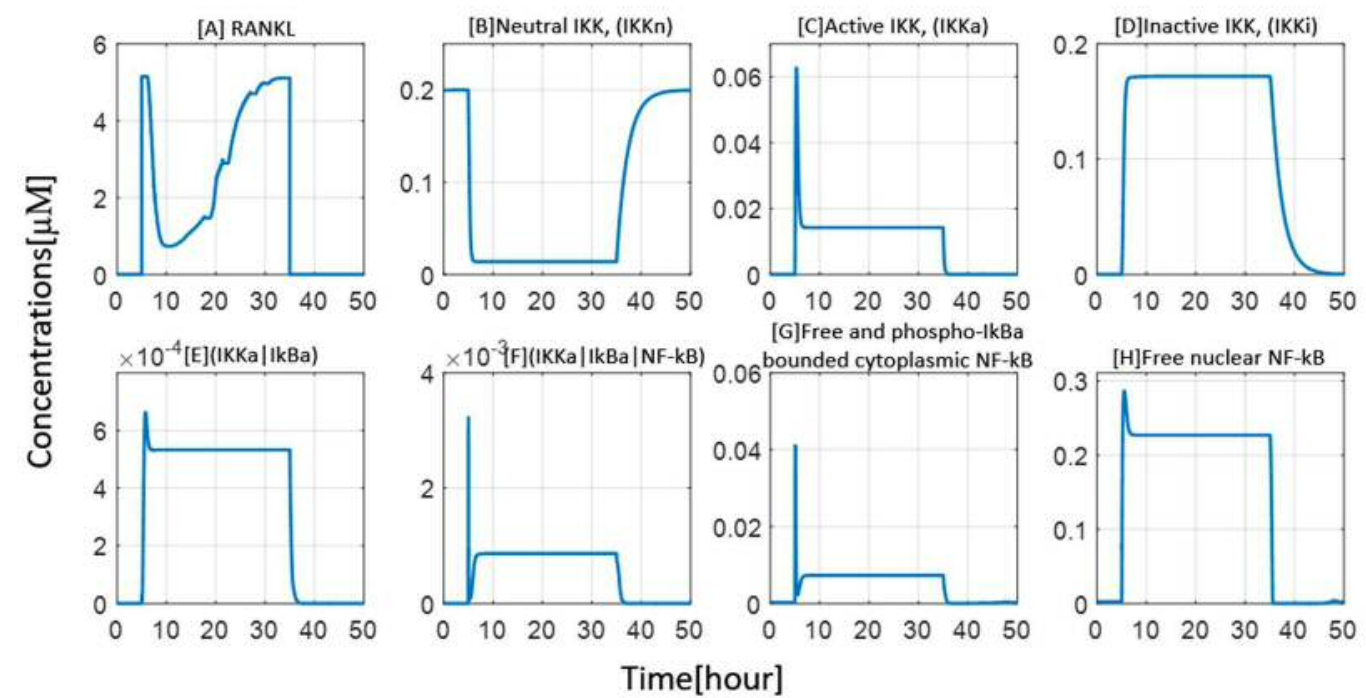

Figure 2: Model simulations of the variation in the concentrations of variables with regard to NF- $\kappa \mathrm{B}$ signalling pathway during different periods: NF- $\kappa \mathrm{B}$ pathway is inactivated from $1^{\text {th }}$ hour to $5^{\text {th }}$ hour, activated by RANKL from $6^{\text {th }}$ hour to $35^{\text {th }}$ hour, and inactivated again from $36^{\text {th }}$ hour to $55^{\text {th }}$ hour. In figure $4 \mathrm{~A}-4 \mathrm{H}$, Time (horizontal axis) is in hours, and concentrations (vertical axis) are given in $\mu \mathrm{M}$. 

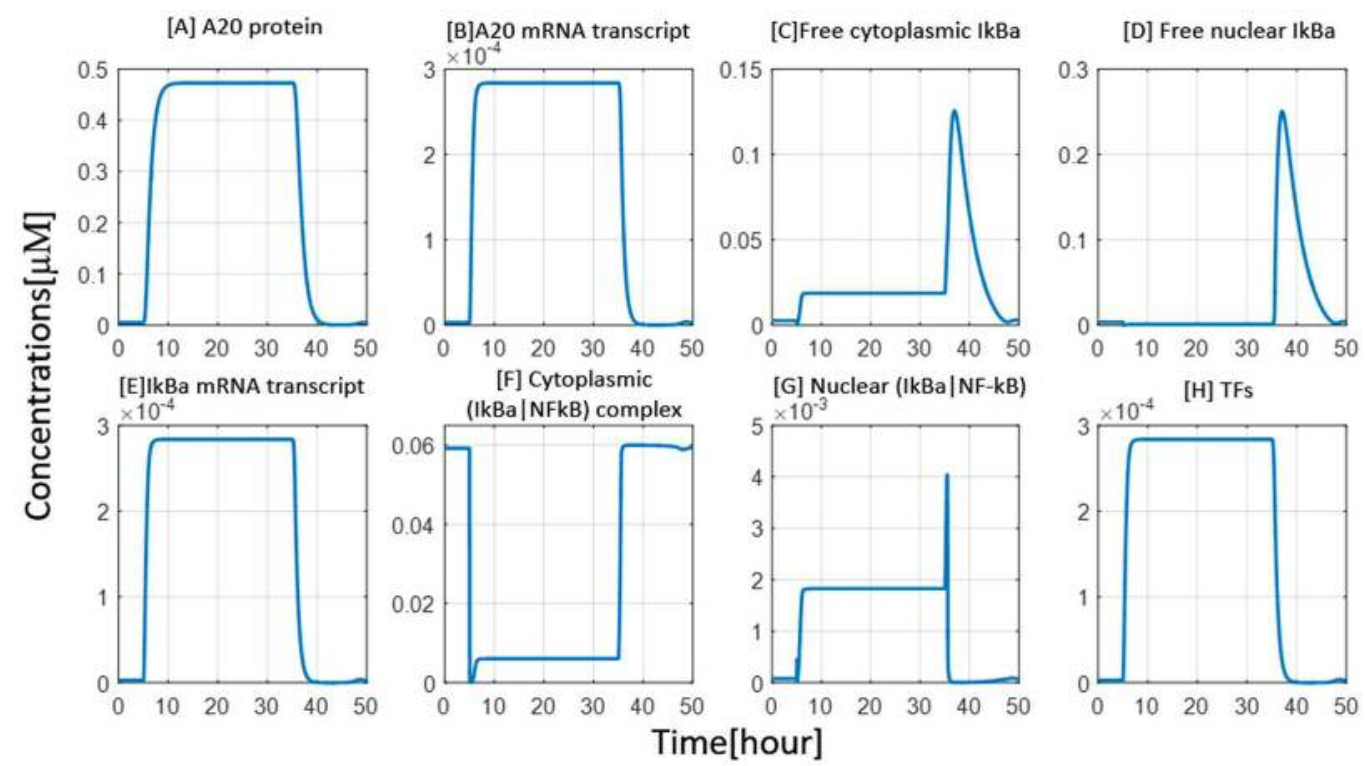

Figure 3: Model simulations of the variation in the concentrations of variables with regard to NF- $\mathrm{NB}$ signalling pathway during different periods: NF- $\kappa \mathrm{B}$ pathway is inactivated from $1^{\text {th }}$ hour to $5^{\text {th }}$ hour, activated by RANKL from $6^{\text {th }}$ hour to $35^{\text {th }}$ hour, and inactivated again from $36^{\text {th }}$ hour to $55^{\text {th }}$ hour. Concentrations (vertical axis) are given in $\mu \mathrm{M}$,and time (horizontal axis) is in hours.

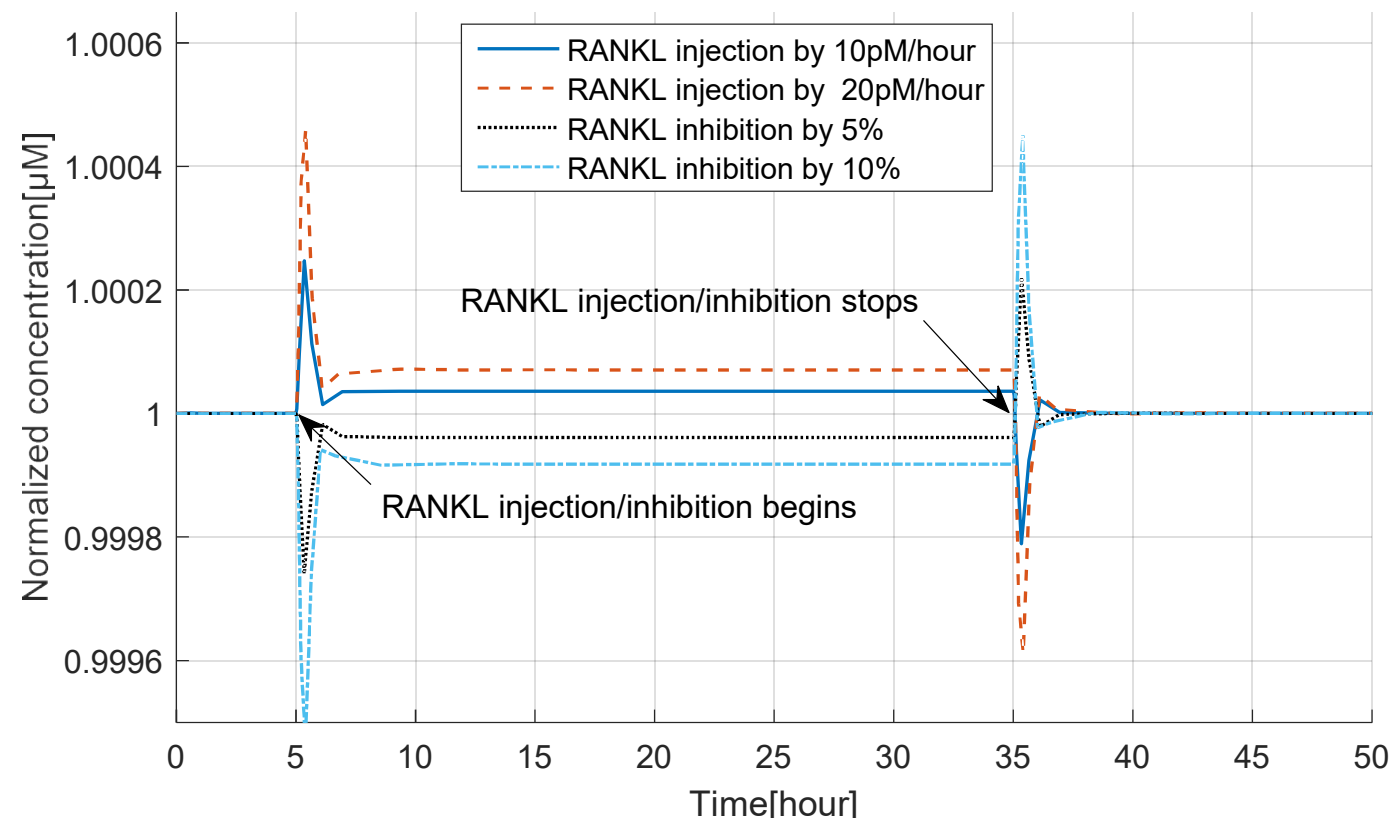

Figure 4: Model simulations of the variation in normalized free nuclear NF-kB with respect to its initial value after injection of RANKL at the rate of 10 or $20 \mathrm{pM} /$ hour, or inhibition of RANKL by $5 \%$ or $10 \%$ from $5^{\text {th }}$ hour to $35^{\text {th }}$ hour. 


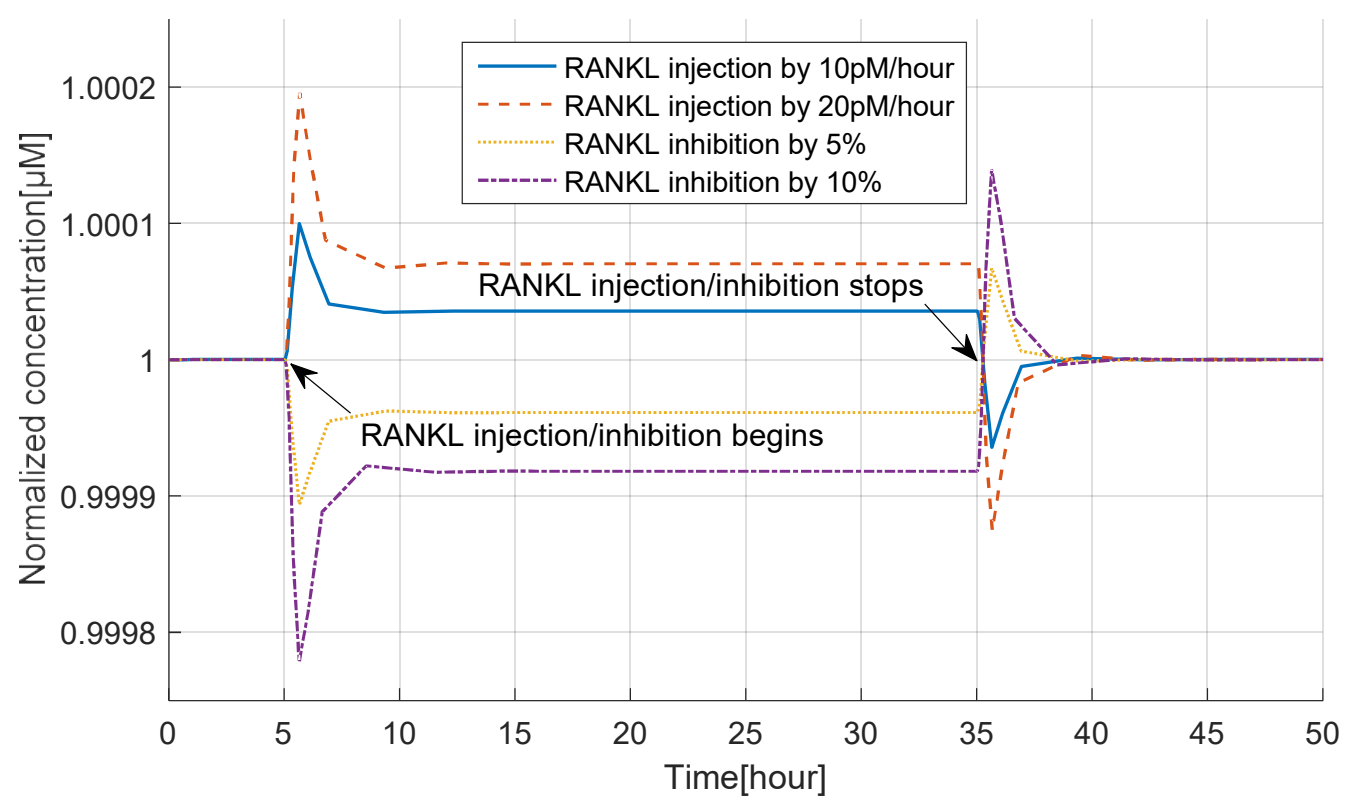

Figure 5: Model simulations of the variation in normalized $T F_{s}$ with respect to its initial value after injection of RANKL at the rate of 10 or $20 \mathrm{pM} /$ hour, or inhibition of RANKL by $5 \%$ or $10 \%$ from $5^{\text {th }}$ hour to $35^{\text {th }}$ hour.

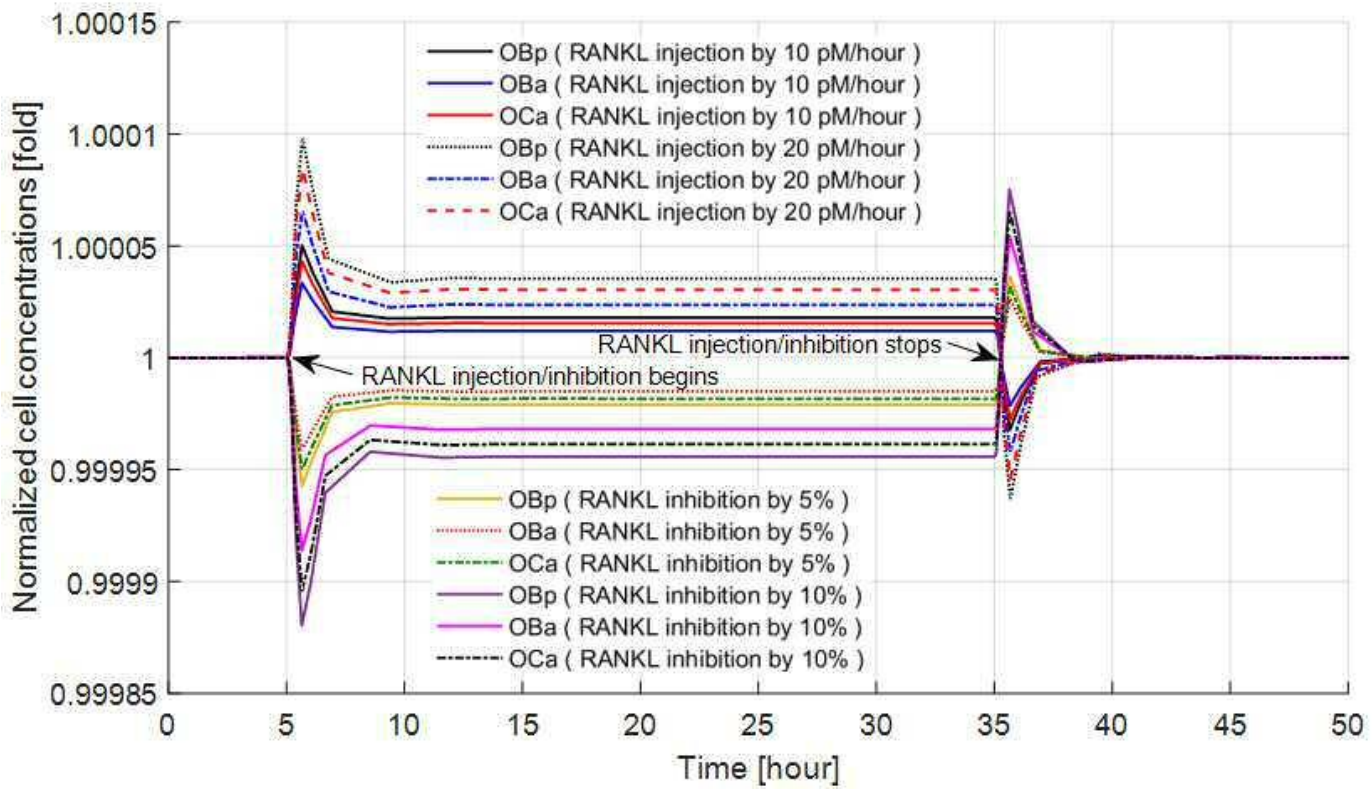

Figure 6: Model simulations of the variation in normalized cell concentrations with respect to its initial value after injection of RANKL at the rate of 10 or $20 \mathrm{pM} /$ hour, or inhibition of RANKL by $5 \%$ or $10 \%$ from $5^{\text {th }}$ hour to $35^{\text {th }}$ hour. 


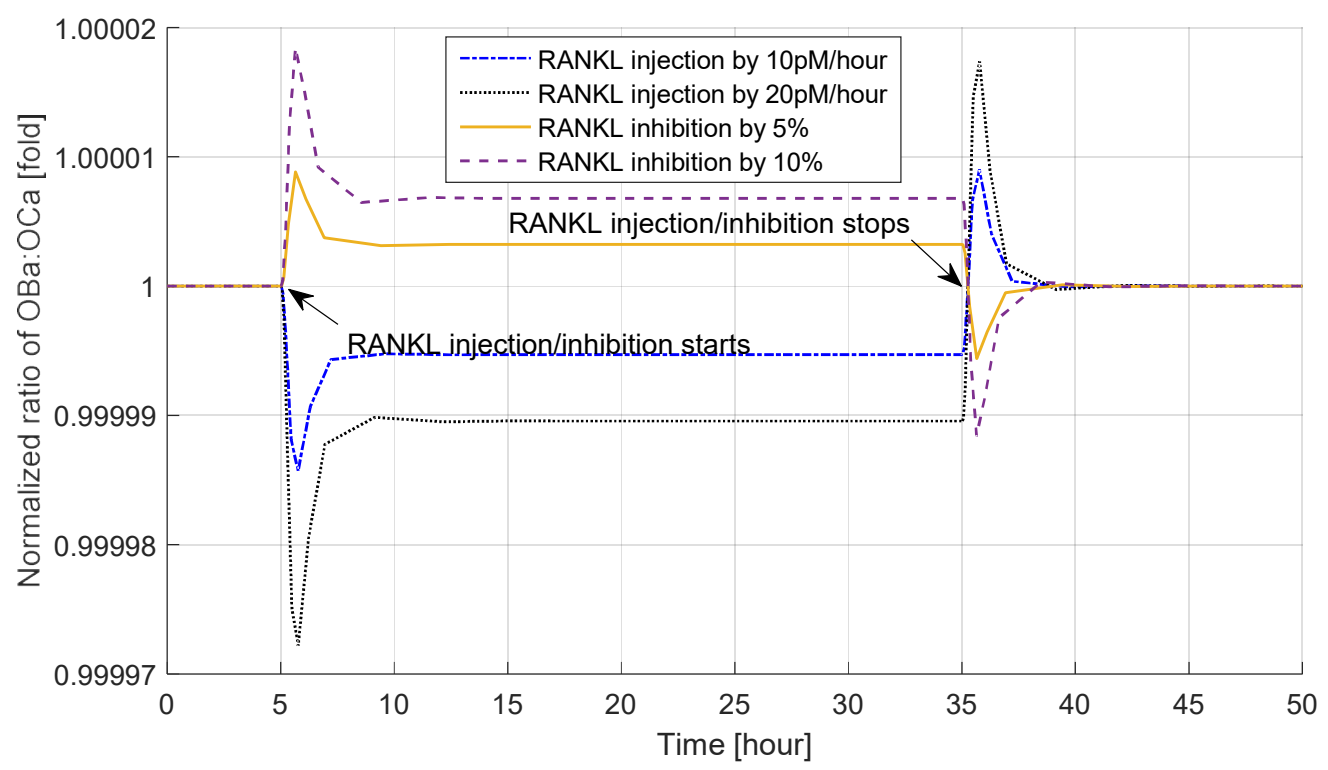

Figure 7: Model simulations of the variation in normalized ratio of $\mathrm{OBa}: \mathrm{OCa}$ with respect to its initial value after injection of RANKL at the rate of 10 or $20 \mathrm{pM}$ /hour, or inhibition of RANKL by $5 \%$ or $10 \%$ from $5^{\text {th }}$ hour to $35^{\text {th }}$ hour.

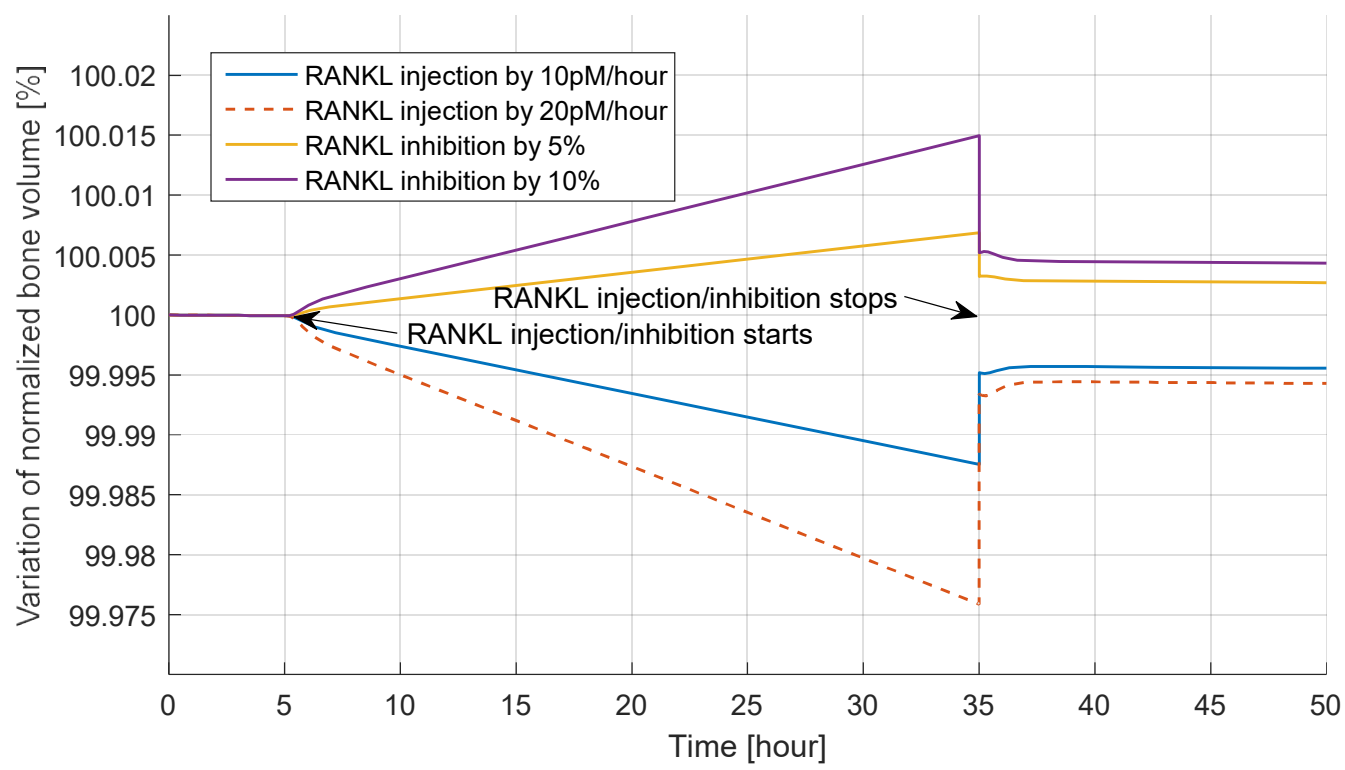

Figure 8: Model simulations of the variation in normalized bone volume with respect to its initial value after injection of RANKL at the rate of 10 or $20 \mathrm{pM} / \mathrm{hour}$, or inhibition of RANKL by $5 \%$ or $10 \%$ from $5^{\text {th }}$ hour to $35^{\text {th }}$ hour. 


\section{Appendix A}

\section{Tables of definitions of the concentrations and $\pi$ functions}

Table A1: Definitions of the concentrations of RANKL, OPG, TGF- $\beta$ and PTH.

\begin{tabular}{|c|c|}
\hline \multirow[b]{2}{*}{$R A N K L$} & $P_{R A N K L, d}+\beta_{R A N K L} \cdot O B_{p}$ \\
\hline & $\left(1+K_{A, O P G} \cdot O P G+K_{A, R A N K} \cdot R A N K\right) \cdot\left(\frac{\beta_{R A N K L}}{R^{R A N K L} \cdot \pi_{a c t, R A N K L}^{I L 6} \cdot \pi_{a c t, R A N K L}^{P T H}}+D_{R A N K L}\right)$ \\
\hline \multirow[b]{2}{*}{$O P G$} & $P_{O P G, d}+\beta_{O P G} \cdot O B_{a} \cdot \pi_{r e p, O P G}^{P T H}$ \\
\hline & $\overline{\left(\frac{\beta_{O P G} \cdot O B_{a} \cdot \pi_{r e p, O P G}^{P T H}}{O P G_{\max }}+D_{O P G}+D_{O P G, M M} \cdot M M\right)}$ \\
\hline \multirow{2}{*}{$T G F \beta$} & $\alpha \cdot K_{r e s} \cdot O C_{a}+S_{T G F \beta}$ \\
\hline & $\widetilde{D}_{T G F \beta}$ \\
\hline \multirow{2}{*}{ PTH } & $\beta_{P T H}+P_{P T H, d}(t)$ \\
\hline & $\widetilde{D}_{P T H}$ \\
\hline
\end{tabular}

Table A2: Definitions of the $\pi$ functions used in the concentration equations in Table A1.

\begin{tabular}{|c|c|}
\hline $\begin{array}{c}\text { TGF } \beta \text { stimulates the differentiation of } \\
O B_{u} \text { into } O B_{p}\end{array}$ & $\pi_{a c t, O B_{u}}^{T G F \beta}=\frac{\mathrm{TGF} \beta}{\mathrm{K}_{\mathrm{D} 1, \mathrm{TGF} \beta}+\mathrm{TGF} \beta}$ \\
\hline $\begin{array}{c}O B_{p} \text { into } O B_{a} \\
\text { TGF } \beta \text { inhibits the differentiation of } \\
\text { TGF } \beta \text { promotes the apoptosis of } O B_{a}\end{array}$ & $\pi_{r e p, O B_{p}}^{T G F \beta}=\frac{1}{1+\left(T G F \beta / K_{D 2, T G F \beta}\right)}$ \\
\hline PTH stimulates the production of & $\pi_{a c t, O C_{a}}^{T G F \beta}=\frac{T G F \beta}{K_{D 3, T G F \beta}+T G F \beta}$ \\
RANKL & $\pi_{a c t, R A N K L}^{P T H}=\frac{P T H}{K_{D 1, P T H}+P T H}$ \\
\hline PTH inhibits the production of OPG & $\pi_{r e p, O P G}^{P T H}=\frac{1}{1+\left(P T H / K_{D 2, P T H}\right)}$ \\
\hline
\end{tabular}




\section{Mathematical model of NF- $\kappa B$ signalling pathway}

$$
\begin{aligned}
& \frac{d}{d t} K K \quad(t)=\operatorname{prod}^{-}{ }_{\operatorname{deg}} K K \quad(t)-R_{f 1}{ }_{1} K K \quad(t) \\
& \frac{d}{d t} K K \quad(t)=R_{f 1}{ }_{1} K K \quad(t)-{ }_{3} K K \quad(t)-R_{f 2}{ }_{2} K K \quad(t) \cdot A 20(t)-\operatorname{deg} K K \\
& \begin{array}{llll}
-{ }_{2} K K & (t) \cdot B \alpha(\mathrm{t})+t_{1}(K K & \mid B \alpha & )(\mathrm{t})
\end{array} \\
& -{ }_{3} K K \quad(t) \cdot\left(\begin{array}{lll}
B \alpha & \mid N F & B
\end{array}\right)(t) \\
& +t_{2}\left(\begin{array}{llll}
K K & \mid B \alpha & \mid N F & B
\end{array}\right)(t) \\
& \frac{d}{d t} K K \quad(t)={ }_{3} K K \quad(t)+R_{f 2}{ }_{2} K K \quad(t) \cdot A 20(t)-\operatorname{deg} K K \quad(t)
\end{aligned}
$$

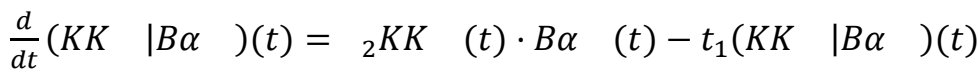

$$
\begin{aligned}
& \frac{d}{d t}\left(\begin{array}{llll}
K K & \mid B \alpha & \mid N F & B
\end{array}\right)(t)={ }_{3} K K \quad(t) \cdot\left(\begin{array}{lll}
B \alpha & \mid N F & B
\end{array}\right)(t) \\
& -t_{2}\left(\begin{array}{llll}
K K & \mid B \alpha & B & B
\end{array}\right)(t) \\
& \frac{d}{d t} N F \quad B(t)={ }_{6 a}(B \alpha \quad \mid N F \quad B)(t)-{ }_{1} N F \quad B(t) \cdot B \alpha \quad(t) \\
& +t_{2}\left(\begin{array}{llll}
K K & \mid B \alpha & \mid N F & B
\end{array}\right)(\mathrm{t})-{ }_{1} N F \quad B(t) \\
& \frac{d}{d t} N F \quad B_{n}(t)={ }_{1} \quad{ }_{v} N F B(t)-{ }_{1} B \alpha \quad{ }_{n}(t) \cdot N F B_{n}(t) \\
& \frac{d}{d t} A 20(t)={ }_{4} A 20_{t}(t)-{ }_{5} A 20(t) \\
& \frac{d}{d t} A 20_{t}(t)={ }_{2}+{ }_{1} N F B_{n}(t)-{ }_{3} A 20_{t}(t) \\
& \frac{d}{d t} B \alpha \quad(t)=-{ }_{2} K K \quad(t) \cdot B \alpha \quad(t)-{ }_{1} B \alpha \quad(t) \cdot N F \quad B(t)+{ }_{4 a} B \alpha \quad{ }_{t}(t)- \\
& { }_{5 a} B \alpha \quad(t)-{ }_{1 a} B \alpha \quad(t)+{ }_{1 a} B \alpha \quad{ }_{n}(\mathrm{t}) \\
& \frac{d}{d t} B \alpha \quad{ }_{n}(t)=-{ }_{1} B \alpha \quad{ }_{n}(t) \cdot N F \quad B_{n}(t)+{ }_{1 a} \quad v \quad B \alpha(t)-{ }_{1 a} \quad{ }_{v} B \alpha{ }_{n}(t) \\
& \frac{d}{d t} B \alpha \quad{ }_{t}(t)={ }_{2 a}+{ }_{1 a} N F B_{n}(t)-{ }_{3 a} B \alpha \quad{ }_{t}(t) \\
& \frac{d}{d t}(B \alpha \quad \mid N F \quad B)(t)={ }_{1} B \alpha \quad(t) \cdot N F B(t)-{ }_{6 a}(B \alpha \quad \mid N F \quad B)(t) \\
& -{ }_{3} K K \quad(t) \cdot\left(\begin{array}{lll}
B \alpha & \mid N F & B
\end{array}\right)(t) \\
& +{ }_{2 a}\left(B \alpha{ }_{n} \mid N F B_{n}\right)(\mathrm{t}) \\
& \frac{d}{d t}\left(B \alpha{ }_{n} \mid N F B_{n}\right)(t)={ }_{1} B \alpha \quad{ }_{n}(t) \cdot N F \quad B_{n}(t)-{ }_{2 a}{ }_{v}\left(B \alpha{ }_{n} \mid N F \quad B_{n}\right)(t) \\
& \frac{d}{d t} T F(t)={ }_{2 c}+{ }_{1 c} N F B_{n}(t)-{ }_{3 c} T F(t)
\end{aligned}
$$

The definitions and values for parameters in above equations can be found in Lipniacki et al. [27] 


\section{Calculation of model parameters based on GA}

$$
\begin{aligned}
F() & =\sum_{i=1: 3} \quad\left(M()_{i}-{ }_{i}\right) \\
& =\left[, \ldots, \quad, K_{o b}, K_{o c}\right]
\end{aligned}
$$

where $\mathrm{X}=\left[K_{D 1, T G F \beta}, K_{D 3, T G F \beta}, K_{D 1, P T H}, K_{D, T F s, a c t}, K_{D I 2, T F s, a c t}, K_{D I 2, T F s, a c t}, K_{\text {res }}\right]$ is a row vector consisting of the seven parameters in the model equations and represents one point in the parameter space; $M()_{i}$ and $P_{i}(=1,2,3)$ represent model outputs corresponding to each point in the parameter space and the preferred model outputs, respectively. 